\title{
Yeniden Yazılan Metinler: Sırça Kümes Ve Sırça Hayvan Koleksiyonu Oyunlarının Oyun Çevirisi Bağlamında İncelenmesi*
}

\section{Rewritten Texts: Comparative Analysis of Sirça Kümes and Sirça Hayvan Koleksiyonu in the Context of Theater Translation}

\author{
Melda Dinçel Enginsu' ${ }^{1}$
}

* Bu makale Prof. Dr. Ayşe Fitnat Ece danıșmanlığında yazılan, "Yeniden Yazılan Metinler: Sırça Kümes ve Sırça Hayvan Koleksiyonu Oyunlarının Oyun Çevirisi Bağlamında İncelenmesi" başııkı yayımlanmamış yüksek lisans tezinden üretilmiştir (İstanbul Okan Üniversitesi, Çeviribilim Yüksek Lisans Programı).

'İstanbul Üniversitesi, Edebiyat Fakültesi, Tiyatro Eleştirmenliği ve Dramaturji Bölümü, İstanbul, Türkiye

\section{ORCID: M.D.E. 0000-0003-4971-5309}

Sorumlu yazar/Corresponding author: Melda Dinçel Enginsu (Doktora Öğrencisi), İstanbul Üniversitesi, Edebiyat Fakültesi, Tiyatro Eleştirmenliği ve Dramaturji Bölümü, Istanbul, Türkiye

E-mail: meldadincel@yahoo.com

Başvuru/Submitted: 22.03.2021 Revizyon talebi/Revision requested: 30.04.2021

Son revizyon/Last revision received: 18.05.2021

Kabul/Accepted: 18.05.2021

\section{öz}

Tiyatrobilim ve Çeviribilim alanlarının disiplinlerarası araştırmaya açık olma özellikleri sayesinde tiyatro metinleri çevirisi çift yönlü araştırma alanı yaratmaktadır. Özellikle birden fazla çevirisi olan ve farklı sahnelerde oynanan oyunların incelenmesi, metinlerin çevrildiği döneme ait çeviri poetikası, yaygın çevirmen stratejileri gibi araştırma alanlarında söylemlerin üretilmesine imkân tanımaktadır. Bu çalışmada André Lefevere'in çeviriyi yeniden yazım olarak nitelendiren kuramıyla bağlantı kurarak, erek dizgede farklı dönemlerde hem basılmış hem de sahnelenmiş iki erek metin ele alınmıştır. Amerikan tiyatrosunun önde gelen yazarlarından Tennessee Williams'ın Birinci Dünya Savaşı sonrasında yaşanan Büyük Buhran döneminde geçen, üç kişilik bir ailenin verdiği yaşam mücadelesini ve eve gelen "misafirin" varlığıyla tetiklenen büyük sonunu konu alan The Glass Menagerie metninin Türkçe edebiyat dizgesinde sırasıyla Milli Eğitim Bakanlığı Yayınları ve Mitos Boyut Yayınları tarafından yayımlanan ve Devlet Tiyatroları ile İstanbul Büyükşehir Belediyesi Şehir Tiyatroları gibi ödenekli tiyatrolar ile özel tiyatrolar tarafından sahnelenen çevirmen Can Yücel'in Sırça Kümes ile çevirmen Aytuğ İzat'ın Sırça Hayvan Koleksiyonu metinleri, Marilyn Gaddis-Rose'un uygulaması olan "üç-boyutlu okuma"yöntemi doğrultusunda karşılaştırmalı olarak okunmuştur. Bu okumada erek metinlerde gözlemlenen çevirmen kararları, tiyatro metinleri çevirisi bağlamında ele alınarak, çevirmenlerin kültürel özelliklerin, tiyatro metinlerinin özelliklerinin ve dilsel anlatım özelliklerinin aktarımındaki seçimleri çeşitli alt başlıklarda incelenerek, çevirmen kararları, yorumları ve çeviri anlayışları olarak yorumlanmıştır.

Anahtar kelimeler: Yeniden yazım, üç boyutlu okuma, tiyatro metinleri çevirisi, Sırça Kümes, Sırça Hayvan Koleksiyonu, The Glass Menagerie

\section{ABSTRACT}

Translation of theater texts creates a two-way research area, thanks to the openness of both Theater Studies and Translation Studies to interdisciplinary research. In particular, examining plays that exist in more than one translation and that have been staged in different arenas enables comparative research into areas such as translation poetics and common translator strategies during the period of the translation. In this study, two target texts, both published and 
staged in different periods, have been scrutinized in connection with the theories of André Lefevere, which characterize translation as rewriting. The texts in question are translations of The Glass Menagerie by Tennessee Williams, one of the leading playwrights of $20^{\text {th }}$ century America. This play, set during the Great Depression in the 1930 s, depicts the life struggles of a family of three, whose biggest problems are triggered by the presence of a "guest."Translations of the play entered the Turkish literary system in the forms of Can Yücel's text Sırça Kümes and Aytuğ İat's text Sırça Hayvan Koleksiyonu, published by the Ministry of Education and Mitos Boyut Publishing respectively. These translations have been staged by state-funded theaters, such as the State Theaters and the Istanbul Metropolitan Municipality City Theaters, as well as by private theaters. The source and target texts were read comparatively, alongside each other according to the "stereoscopic reading" method of Marilyn Gaddis-Rose. In this comparative reading, the translators' decisions, as observed in the target texts, were analyzed in the context of the translation of theater texts. The choices made, in terms of the transfer of cultural characteristics, characteristics of theater texts, and linguistic expressions, were examined under various sub-headings and explained as translator's decisions, versions, and interpretations.

Keywords: Rewriting, stereoscopic reading, dramatic text translation, Sırça Kümes, Sırça Hayvan Koleksiyonu, The Glass Menagerie

\section{EXTENDED ABSTRACT}

Tennessee Williams was one of 20th century America's most important playwrights. Williams' The Glass Menagerie was written in 1944 and premiered by the Playhouse Theater in 1945. The Glass Menagerie has two different translations in the Turkish literary system, the earlier of which is Can Yücel's Sırça Kümes, published by the Ministry of National Education in 1964. Since its release, Sirça Kümes has been met with great interest and has been staged by both private and state-funded theaters, such as the State Theaters. The other translation is Aytuğ Izat's Sırça Hayvan Koleksiyonu, published by Mitos Boyut Publications in 2000. This text, supported by the American Consulate and published as part of the Cultural Heritage Project, was added to Istanbul Metropolitan Municipality City Theater's repertoire and was first staged in the 2014-2015 season.

This study aims to examine the translated texts in light of André Lefevere's theories on rewriting. In the preface to their book Translation/History/Culture, Susan Bassnett and André Lefevere state that every translation/rewriting strategy develops in line with ideological and literary reasons related to the text (Bassnett \& Lefevere, 1992: xi). When translated or rewritten texts are examined in this way, it is possible to treat the translator's unique behaviors as a subject of inquiry and to produce a detailed opinion of the time and environment in which the translation was performed.

The study is organized in three parts. The first focuses on the theoretical framework of translation as rewriting and theater text translation. In the second part, the definitions established in the first part are applied to the process of scrutinizing the translations, and the two translated target texts are examined alongside the source text within the framework of Marilyn GaddisRose's concept of "stereoscopic reading."." Finally, the processes underlying the production of the two translations are analyzed under the subtitles Usage of Slang, Usage of Idioms, Expressions Related to Staging Process, Expressions Related to Target Culture, Expressions 
Related to Source Culture, and Title Preference. Differences between translators' selections are explained according to these characteristics.

To reflect the characters' spoken language in the target text, Can Yücel employed idiomatic and slang elements that stand out in the daily use of the target language. Yücel's choice can be considered an effort to prevent the target audience from attracting a stranger to a work that belongs to the source language and culture system. Taking the staging notes into account, Yücel created a text ready to be staged by reflecting the directions given by Williams, the original playwright, in the source text. By contrast, Aytuğ İzat's translation uses everyday language within the semantic range of the words in the source text, reflecting his desire to protect the linguistic and cultural features of the source system and to provoke an emotional response in the target audience. İzat's translation preserves the source language and culture system and thus represents a resource-oriented translation. It can be considered a text that allows directors' decisions to come to the fore in the staging process, ignoring both staging notes and actor directions.

In conclusion, differences in the translators' interpretation of the source text were reflected in both target texts in line with the translators' different reading processes. These differences can be recognized as translator decisions that enrich and develop the target language and culture system. Within the scope of the study, the shaping of the translation process and the differences between the translators' discourses (tracked in the target system by comparison with characteristics of the source text's own language and culture system) can be analyzed in the context of rewriting. Thanks to the different paths chosen by the translators, Can Yücel and Aytuğ İzat, the source text is re-created in the target system. In other words, the study shows that the translators reached noticeably different destinations despite using the same source, writing the same yet different plays in the target system. These play texts, which have assumed and preserved a place for themselves in the target literary system, have continued to meet with audiences in the theater halls. It is important for a target text to be represented by more than one translation in a target literary system, both for the reader and the system itself. The richness created by this diversity stimulates further development of the literary system, progress among readers and audiences, and the expansion of creativity. 


\section{Giriş}

Yirminci yüzyıl Amerikan tiyatrosunun en önemli yazarlardan Tennessee Williams'ın 1944 yılında yazdığı ve ilk olarak 1945 yılında Playhouse Theatre tarafindan sahnelenmeye başlanan The Glass Menagerie adlı eserinin Türkçe edebiyat dizgesinde iki farklı çevirisi bulunmaktadır. Bunlardan ilki Millî Eğitim Bakanlığı tarafından 1964 yılında yayımlanan ve çevirisini Can Yücel'in yaptığı Sırça Kümes ’tir. Sırça Kümes oyunu yayımladığından itibaren büyük ilgiyle karşılanmış ve başta Devlet Tiyatroları olmak üzere ödenekli ve özel tiyatrolar tarafından sahnelenmiştir. Diğer çeviri ise Mitos Boyut Yayınları tarafindan 2000 yılında yayımlanan Aytuğ İzat'ın imzasını taşıyan Sırça Hayvan Koleksiyonu'dur. Amerikan Konsolosluğu tarafından desteklenen ve Kültür Mirası Projesi kapsamında basılan bu oyun metni 2014-2015 sezonunda İstanbul Büyükşehir Belediyesi Şehir Tiyatroları tarafından sahnelenmeye başlamıştır.

Bu çalışmada André Lefevere'in yeniden yazma yaklaşımının rehberliğinde çeviri metinleri erek kültürün anlayışına uygun koşullarda anlamlandırabilmek ve çevirmenin dünyasını daha iyi tanıtmak amaçlanmıştır. Susan Bassnett ile André Lefevere'in editörlüğünü yaptığ 1 Translation, History, and Culture kitabının önsözünde, her çeviri/yeniden yazım stratejisinin, metinle bağlantılı olan ideolojik ve edebi nedenler doğrultusunda geliştiği belirtilmektedir (Bassnett, Lefevere, 1992: xi). Çeviri metinler ya da yeniden yazılmış metinler bu açıdan ele alındığında çevirmenin bir özne olarak kendine özgü davranışlarını betimlemek ve eylemin gerçekleştirildiği zaman ve ortamla ilgili düşünce üretmek mümkün olmaktadır.

\section{Amaç ve Yöntem}

\subsection{Yeniden Yazım Olarak Çeviri}

İki dil arasında kendi sistemini kuran ve iki dizge arasındaki farklılıkları gözeterek erek metin üretebilen çevirmenin ideolojik, kültürel, sosyolojik, politik ve ekonomik değeri yalnızca çeviri eylemiyle sınırlandırılmamalıdır. André Lefevere'in 1992 yılında yayımlanan Translating, Rewriting and the Manipulation of Literary Fame kitabında ileri sürdüğü yeniden yazım düşüncesine göre "yeniden yazan kişi, bir yazarın, eserin, dönemin, türün ve bazen bütün bir edebiyatın imgelerini yaratmaktadır" (Lefevere,1992: 5) ${ }^{1 *}$. Bu imgelerin sahip olduğu güç düşünüldüğünde, yeniden yazılmış metinlerin belli bir amaç uğruna ya da dayatmalar ve ideolojik akımların doğrultusunda gerçekleştirildiğini söyleyen Lefevere, kaynak metinlerin saygınlığını kullanan yeniden yazılmış metinlerin kabul edilmesinin daha kolay olduğunu söylemektedir (a.g.e.: 5). Dolayısıyla yeniden yazma eyleminin arkasındaki genel görüş ideolojik ya da edebi kaygılarla şekillenmektedir.

Yeniden yazma eyleminin, tarih yazarlığı, eleştiri ve editörlük alanlarında aynı temel üzerine kurulduğunu söyleyen Lefevere'e göre, "Çeviri, yeniden yazmanın en ayırt edilebilen türüdür ve

1 *Aksi belirtilmedikçe İngilizce kaynaklardan yapılan alıntıların çevirisi tarafıma aittir. 
en etkili olanıdır çünkü yazarın ve kaynak kültürün sınırlarının ötesindeki eserlerin imgelerini yansitabilmektedir" (a.g.e.: 9). Bu bağlamda ele alınan çeviri eserler, erek dizgede var olma olană̆1 elde etmektedir. Kaynak metnin gölgesinde kalan ve ikincil pozisyonda değerlendirilen erek metinler, çevirmenin eseri olarak erek dil yoluyla erek okuyucuya ulaşmakta ve erek kültür dizgesine yerleşmektedir.

Rus Biçimcilerin geliştirdiği "Sistemlerin Sistemi'nden” söz eden Lefevere, sistemlerin birbirinden etkilenmeye açık olduğunu ve bu etkinin kontrol altında tutulduğunu söylemektedir. Edebiyat sistemi içinde kontrol anlamında etkin olan üç öğe ise, sistem içindeki profesyoneller, sistemi dışarıdan etkileyen hamiler ve poetika olarak belirlenmektedir. Lefevere'e göre "Sistemin profesyonelleri, eleştirmenler, öğretmenler ve çevirmenlerdir" (a.g.e.: 14). Bu gruba dahil olan kontrol mekanizmaları, dönemin şartları dahilinde eser seçiminde ve yaygınlaştırılmasında etkin rol oynamaktadır. Dolayısıyla profesyonel kontrol mekanizmaları, okuyucuyu da sisteme dahil ederek dizgenin devamlılığını sağlayan etmenler olarak da ele alınabilir. Diğer bir öğe olarak belirlenen ve sistemin dışında olmasına rağmen büyük bir etkisi olan hamilik ise gücü ifade etmektedir. Bu gücün, “eserlerin edebi özelliklerinden ve değerlerinden çok ideolojileriyle ilgilenmesi, eserlerin seçiminde ya da yaygınlaştırmasında, eserlerin dağıtımında, pazarlanmasında ya da okunup okunmamasında kişi ya da kurumların yönlendirmesinin önemini göstermektedir" (a.g.e.: 15).

Sanat ve edebiyat tarihinde önemli bir yer tutan hamiliğin üç öğeden oluştuğunu söyleyen Lefevere bunları ideolojik unsurlar, ekonomik unsurlar ve statü olarak sıralamaktadır (Lefevere, 1992: 16). Eğer bu faktörlerin üçü de aynı kişi ya da kurum tarafından sağlanıyorsa hamilik farklılaştırılmamıştır. Fakat "ekonomik başarının ideolojik nedenlerden bağımsız olması ve sonucunda kısmi statü kazandırmaması farklılaşmış bir hamilik olduğunu göstermektedir" (a.g.e.: 17). Hamiliğin edebiyat dizgesi üzerindeki etkisi bu üç faktöre göre değişiklik gösterse de edebiyat dizgesinin gelişimi ya da değişimi üzerindeki etkisi sabittir. Eserlerin seçimi, yazar ve çevirmenlerin teşvikiyle var olan edebiyat dizgelerin geliştirilmesi ya da yeni dizgelerin oluşturulması, hamilerin beklentilerine göre gerçekleşmektedir. Bu beklentilerin doğrultusunda yapılan değişikliklerin de okuyucular tarafından onaylanması kısır bir döngü yaratmakla kalmıyor, ideolojik, ekonomik ve statü etmenlerinin güce hükmetmelerine ve poetikanın yönetiminde farklı kodlamalar oluşturmalarına neden olur. Dolayısıyla hami ve okuyucu arasındaki bağı kuran çevirmenler, aynı zamanda kendi seçimlerinin kurbanı olabiliyor ve edebiyat dizgesini çıkmaza sürükleyebilmektedir. Bu bağlamda çevirmenlerin sadece kültürlerarası değil kültür içi elçilik yaptığı da söylenebilir.

Sistemin üçüncü öğesi olarak poetikadan söz eden Lefevere, baskın edebi anlayışı da ikiye ayırmaktadır. Bunlar: "türler, semboller, durumlar ve karakterler olarak ele alınan edebi araçlarla, sosyal sistem içinde, seçili temalar dahilinde etkili olan edebiyatın rolüdür" (a.g.e.: 26). Poetika, dönemin edebiyat alışkanlıklarından oluşan bir sistem dahilinde düşünülebilir. Gerek kuramsal gerek geleneksel yapının oluşturduğu bu alışkanlıklar, edebiyat eserlerinde 
kullanılacak öğeleri belirlemekte ve edebiyat dizgesinin merkezine dolaylı yoldan müdahale etmektedir. Edebiyatın toplumsal rolü de göz önünde bulundurulduğunda poetikanın önemi çeviri incelemeleri ya da dönemsel edebiyat incelemelerinde açığa çıkmaktadır.

Sistemin bu öğelerinin edebiyat dizgesi içinde yer alan bütün etmenlerin üzerinde doğrudan ya da dolaylı yoldan etkisi olduğunu göz önünde bulunduracak olursak, çevirmenin konumu üzerine daha gerçekçi bir bakış açısıyla düşünebiliriz. Kaynak metinle erek okuyucu arasında köprü kuran çevirmen, kaynak kültürden aldığı imgeleri yeniden yazma/yaratma sürecinde iki önemli faktörden etkilenmektedir. Bunlardan biri çevirmenin ideolojisi (bu ideolojiyi kendi isteğiyle sahiplenmiş olabilir ya da söz konusu ideoloji bir hami tarafından dayatılmış olabilir), diğeri ise çevirinin yapıldığg dönemde erek edebiyat dizgesine egemen olan poetikadır. İdeoloji, çevirmenin kullanacağı temel stratejiyi işaret etmekte ve dolayısıyla hem kaynak metinde ifade edilen 'söylem evreniyle' (kaynak metnin yazarının ailesi olan dünyanın amaçları, kavramları ve alışkanlıkları) hem de kaynak metnin ifade edildiği dille alakalı sorunların çözümlerini de belirtmektedir (a.g.e.: 41). Lefevere'in kitabında söz ettiği iki tür çevirmen vardır. Bunlardan ilki, ideolojik ve poetik açıdan tutucu davranışlar sergileyen ve çeviriyi kaynak kültürün taşıdığı ideolojik ve edebi saygınlığg gözeterek yapan sadık çevirmendir [faithful translator]. Dolayısıyla kaynak kültürün sahip olduğu bu saygınlık ne kadar büyükse, çeviri de "dilbilgisi ve mantık" açısından o kadar doğru olur (a.g.e.: 49-50). Yaratıcı çevirmen [spirited translator] ise kaynak kültürün saygınlığı karşısında tutucu davranmaz. Tam tersine okuyucusunu şaşırtabilmek ve kaynak eserin "klasik" statüsünü biraz olsun değişme noktasına getirebilmek için bazı “güncellemeler" yapar. Yeniden yazmayla, okuyucusunu hem kaynak metnin saygınlığını hem de erek dizgedeki poetik ve ideolojik yorumunu sorgulamaya iter (a.g.e.: 50).

Çevirmeni etkileyen ideolojik etmenler, güç hamileri ve dönemin poetikası, aynı zamanda yeniden yazmanın sonucu olan eserin de ideolojik dengeler doğrultusunda ve poetikanın söylemsel ya da dilsel özellikleri dahilinde değişime uğramasına neden olmaktadır. Yazarın, kaynak kültürün ve dilin sınırından alınan ve çevirmenin yeniden yazma sırasında belirlediği stratejisine ve profesyonel yatkınlığına göre şekillenen eserler, bu dört katmanın (ideoloji, poetika, söylem evreni ve dil) incelenmesiyle varılan noktayı göstermektedir.

Çeviribilimci Marilyn Gaddis-Rose 1997 yılında yayımladığı Translation and Literary Criticism: Translation as Analysis başlıklı kitabında edebiyat eleştirisi ve edebiyat çevirisi arasındaki bağın birbirini beslediğini ve zenginleştirdiğini anlatmaktadır. André Lefevere gibi Marilyn Goddis-Rose da çevirmenin belli bir dönem içerisinde, belli bir ideolojik görüş ile çeviri yaptığını ve bu etkilerin izinin erek metin üzerinde sürülebileceğini söylemektedir (Gaddis-Rose, 1997: 7). Gaddis-Rose edebiyat çevirisi ve edebiyat eleştirisi arasındaki bağın temelini şu şekilde açıklamaktadır: "Çeviri de edebiyat eleştirisi de telif yasaları dahilinde, kendinden önce yazılmış bir metinden üretilmektedir” (a.g.e.: 12). Edebiyat çevirisini, bir edebi metnin kendine özgü yapısını farklı bir dile aktarım olarak değerlendiren Gaddis-Rose, her bir edebiyat çevirisinin edebiyat eleştirisi olarak görülebileceğini söylemektedir (a.g.e.: 13). 
Edebiyat eleştirisi yazılarında olduğu gibi, çevirmen de bir kaynaktan beslenmekte ve sonucunda erek dizgeye yeni bir eser kazandırmaktadır. Bu görüşten yola çıkarak çevirmenin, çeviriye başlamadan önce bir eleştirmen gibi kaynak dilin yapısına ve biçemine göre oluşturulmuş edebiyat metnini incelediğini ve erek dile aktarımı sırasında nasıl bir yol izlemesi gerektiğine karar vermesinin ardından ortaya çıkan erek metinle bir üst-metin yarattı̆̆ını söyleyebiliriz.

Gaddis-Rose'a göre çeviri, "edebiyat tarihinin hareket gücünü ve normlarını yansıtmaktadır" (a.g.e.: 23). Charles Baudelaire'in eserlerinin çevirilerinden örnekler veren Gaddis-Rose, aynı ve farklı erek diller içerisinde aynı metinler kapsamında çeviri etkinliğinin çoğaltılmasına ve dolayısıyla birden çok erek metne ihtiyaç olduğunu, ancak bu şekilde okuyucuların çeviri edebiyat dizgesinde yer alan kaynak metnin farklı mesajlarını bir araya getirebileceklerini belirtmektedir (a.g.e.: 41). Çeviri edebiyatın, erek dizgelerdeki yerini erek metinlerin karşılaştırmasıyla belirlemeye çalışan Gaddis-Rose, dizge incelemesiyle aynı kaynak metinden üretilen erek metinlerin zaman içinde değişen üslup ve ideolojik etkenler dolayısıyla taşıdığı farklı sözcük ve cümle yapılarının izinin sürebileceğini söylemektedir. Erek dizge içinde egemen olan normların doğrultusunda geliştirilen çeviri stratejilerinin tespitinin yalnızca edebiyat tarihçilerinin işine yarayacağını söyleyen Gaddis-Rose, bu araştırma yöntemiyle okuyucunun kaynak ve erek metni deneyimlemesi ve bu deneyimlerin sonucunda ortaya çıkan yeni düşünce alanları hakkında bir bilgiye ulaşılamadığını belirtmektedir (a.g.e.: 53).

"Üç-boyutlu okuma” yöntemi çeviribilimci Ayşe Ece'nin Edebiyat Çevirisinin ve Çevirmeninin İzinde adlı kitabında bahsettiği üzere 1989 yılında ilk defa çevirmen ve eğitimci Joanne Englebert tarafindan uygulanmıştır (Ece, 2010: 44). “Üç boyutlu okuma” yöntemine gönderme yapan Gaddis-Rose'a göre de çeviri metinler, kaynak ve erek dizgede yer alan diğer metinlerle birlikte incelenmeli ve deneyimleri birlikte geliştirmelidir: "Çevirmenin kaynak metni nasıl alımladığını göstermek üzere, kaynak metin ve çeviri arasındaki etkisel ve anlamsal alanı belirlemek için iki metni, açarak ve genişleterek, bir araya getirmeliyiz” (Gaddis-Rose, 1997: 55).

\subsection{Tiyatro Çevirisine Yaklaşımlar}

Oyun metinlerinin en önemli özelliği edebi ve görsel kodları bir arada bulundurması, yani sahnelenmek üzere yazılmış edebi metinler olmasıdır. Dolayısıyla oyun çevirisi üzerinde araştırma yaparken üzerinde durulması gereken nokta, tiyatronun hem bir edebiyat dalı hem de bir sanat dalı olarak incelenebilmesidir. Çeviribilim alanında özellikle oyun çevirileri üzerine uygulamalı ve kuramsal çalışmalar yapan Susan Bassnett 1980 yılında yayımladığı Translation Studies kitabının "Translating Dramatic Texts” adlı bölümde "oyun metinlerinin tamamlanmamış bir metin olarak okunması gerektiğini ve metnin tam anlamının yalnızca sahnede ortaya çıkabileceğini” belirtmektedir (Bassnett, 2002: 124). Bu da çevirmen için sorunun başlangıcı demektir: Metnin dramatik özelliklerini bir kenara bırakmalı mı ya da örümcek ağı gibi metne işlenmiş olan sahneleme öğelerini de erek metne yansıtmalı mı? Robert Corrigan’ın 
dildeki hareketliliğin, ritmin ve duraksamaların erek metne yansıtılması gerektiğini vurgulayan görüşüne değinen Bassnett, oyun metninin sahneleme yöntemleri dışında da oynanabilirlik özelliği taşıdığını belirterek çevirmenin bu özelliğin üzerine kurulduğu yapıları tespit ederek dilbilimsel ve biçimsel kaydırmalar pahasına onları erek metinde yeniden yaratmasının önemine dikkat çekmektedir (a.g.e.: 125-126). Dolayısıyla, çevirmenler oyun metinlerinin hem dilbilimsel ve biçemsel özelliklerini hem de sahne ve seyirciyle olan kesintisiz bağını çeviri süreçlerinde göz önünde tutma sorumluluğunu taşırlar.

Çevirmen, oyun metninde kullanılan kaynak dilin ve kullanacağı erek dilin sürekli bir değişim içinde olduğunu göz ardı etmeden "konuşma ritmi, günlük dil kullanımı, toplumsal konum, ton ve biçem" gibi değişikliklere göre stratejisini belirlemelidir (a.g.e.: 35). Bu stratejileri beş madde halinde sıralayan Bassnett, "tiyatro metnini bir yazın yapıtı olarak ele almak" maddesinde kaynak metne bağlılık stratejisini vurgularken, bu stratejinin yazarın eserlerinin sahnelenmek için değil, okunmak için çevrildiği durumlarda tercih edildiğini vurgulamaktadır (a.g.e.: 35). Bir diğer strateji olarak belirttiği, "Kaynak dilin ekinsel bağlamını çerçeve olarak kullanmak" maddesinde yabancılığını koruyan çeviri anlayışı gibi bir yöntemden söz edilmesine rağmen, ortaya çıkan erek metinler genellikle ideolojik kayma yaratmaktadır (a.g.e.: 35). “'Sahnelenebilirlik' özelliğini çevirmek” maddesinde ise erek metnin sahne metni olarak üretilmesi önceliğinden söz edilmektedir. 'Sahnelenebilirlik' teriminin kesin bir yarg1 içermemesinden kaynaklanan stratejik bir belirsizlik olsa da Bassnett'a göre 'sahnelenebilirlik', kaynak dildeki "yöresel söyleyişleri” erek dildeki “yöresel söyleyişlerle” karşılamak, "eşdeğer karşılıklar" bulmak ve kaynak dilde yer alan tutucu öğeleri çıkartmak gibi özellikleri içermektedir (a.g.e.: 36). "Kaynak dilde koşuk tiyatronun değişik seçeneklerle yaratılması" maddesi kaynak metnin türünün dayattığı dilsel özelliklere sadık kalmak olarak düşünülebilir. Son strateji olan "ortak çeviri” ise kolektif çalışmaya işaret etmesiyle sahne metni üretmek açısından oldukça verimli bir seçenek olarak öne çıkmaktadır. Kaynak dili bilen kişiyle, yani çevirmenle yapımda yer alan kişi, yönetmen ya da oyuncu, birlikte çalışarak 'sahnelenebilirlik' açısından değerli bir erek metin üretirler. Dolayısıyla "çevirmen(ler) hem dil öğelerini hem de görsel öğeleri gözeterek yazılı ve sözlü dil kodları bir arada olan bir metin sunmuş olur” (a.g.e.: 36). Luigi Pirandello'nun "Illustrators, Actors and Translators" başlıklı yazısında çevirmenlerin kaynak metinleri yeniden yorumladığını ve dolayısıyla yeniden yazdıklarını söylediğini belirten Bassnett, sadakatin "yorumlama girişimine girilmediği zamanlarda var olabileceğini” söylemektedir (a.g.e.: 37). Birinci stratejide yer alan kaynak metne sadakat göndermesi haricinde, Bassnett'ın özetlediği bütün stratejiler yeniden yazma bağlamı içinde incelenebilir.

Tiyatro alanında hem performans hem de anlambilim ve kültürlerarası etkileşimler konularında araştırmalar yapan Patrice Pavis, 1999 yılında yayımladığı ve dilimize Sibel Kamber tarafından çevrilen Sahneleme: Kültürler Kavşağında Tiyatro isimli kitabında, çeviri sorunlarını incelemek için iki maddeyi göz ardı etmemek gerektiğini söylemektedir:

1) Tiyatroda çeviri, oyuncuların bedeninden ve seyircilerin kulaklarından geçer. 2) Yalnızca bir dilsel metni bir başkasına çevirmekle kalınmaz, sahne sayesinde türdeş olmayan, uzamla 
ve zamanla birbirinden ayrılmış sözceleme durumları ve kültürler birbiriyle karşı karşıya getirilir ve birbirleriyle iletişim içine konur. (Pavis, 1999: 153-154)

Pavis yazılan, çevrilen ve dramaturji analizi yapılan oyun metninin sahne metni olarak seyirci karşısına çıkmadan önce dört aşamadan geçtiğini söyleyerek bunları "somutlaştırmalar dizisi" olarak adlandırmaktadır. "Metinsel somutlaştırma" olan birinci aşamada çevirmen "kim kiminle ve ne amaçla konuşmaktadır?" sorusunu sorarak önce "makro-metinsel bir çeviri, yani metnin aracı olduğu yapıtın dramaturjik analizini” yapmaktadır (a.g.e.: 156-157). Yani çevirmen, kaynak metnin alt-metnine uzanarak, karakter analizi, yer ve zaman belirlemesi, yazarın ideolojik yaklaşımları gibi metnin ayırt edici özelliklerini belirlemektedir. İkinci aşama olan "dramaturjik somutlaştırma"da belirlenen özelliklerin erek metinde kullanmak üzere çevirisi yapılır. Bu çeviriyle birlikte çevirmen, erek seyirci kitlesinin bir durumu ya da karakteri anlatmak için bir dizi bilgi sağlamış olur (a.g.e.: 158). Üçüncü aşamada, "sahnesel sözceleme" somutlaştırması yapılır. Pavis'e göre bu aşama çoğunlukla atlanır, çünkü çevirmenlerin metinle olan ilişkisi sahnelenmeden önce bitmiş olur (a.g.e.: 158). Günümüzde birçok oyun metni çevirmeni provalarda yer alarak sahne metni oluşumuna dahil olmaktadır. Dolayısıyla hem sahne zamanlaması hem de seyirci algısına yönelik seçilecek "sahnesel sözceleme" aşamasının geçerli ve güncel olduğunu söyleyebiliriz. Dördüncü ve son aşama olan "alımsal somutlaştırma" ya da "alımsal sözceleme" ise erek metnin seyirciyle ulaştığı ve "dokunduğu" aşamadır. Böylece seyirci metni somutlaştırır ve kendine mal eder (a.g.e.: 159). Pavis’e göre sahneleme amacıyla yapılan çeviriler "hem bir dramaturjik analiz hem bir sahneleme hem de seyirci kitlesine sesleniştir” (a.g.e.: 159).

Bassnett'a göre oyun metinleri çevirisinde dikkat edilmesi gereken husus, kaynak kültürün normlarının ve sınırlarının kaynak metnin oluşumundaki etkisi gibi erek kültür normlarının ve sınırlarının da çevirinin oluşumunda kaçınılmaz bir rol oynadığıdır (Bassnett\&Lefevere, 1998a: 93). Pavis'e göre de çevirmenin, oyun metinlerinde sözcüğün ve jestin, dramatik metni bozma ve çevirisini olanaksız kılma tehlikesine karşın, bu sistemleri birbirinden ayırmadan ve hiçbirini göz ardı etmeden kaynak metinden erek metne doğru bir yol çizmesi gerekmektedir (Pavis, 1999: 173).

İki araştırmacının da ortak bağlamı metinlerin yaratımında etkin rol oynayan kaynak ve erek kültürün ideolojik ve sosyal yapılarıyla bu yapıların erek metne sistemler olarak yansımasıdır. Yazın türlerinin dilbilimsel ve biçemsel kodlarının, tarihsel olaylardan etkilenmemesi söz konusu değildir. Ayrıca her metnin çevirisi ait olduğu türün özellikleri ve erek dilin olanakları dahilinde yapılmalıdır. Dolayısıyla oyun metinleri çevirilerinde, oyun metinlerinin özelliklerinin göz önünde bulundurulması ve çeviri sürecinin ve erek metnin hem kültürel dizge hem de edebi dizge içerisindeki bağlamlar içinde incelenmesi araştırmacıların gerçek tiyatro dünyasını büyük ölçüde yansıtabilecek sonuçlara ulaşmasına yardımcı olabilecektir.

Oyun çevirisi üzerine geliştirilen düşünce ve söylemlere çift taraflı bakış açısıyla yer verildiğinde, oyun çevirisindeki sorunların hem çeviribilim hem de tiyatrobilim alanlarında 
söz ve eylemin erek dil ve kültür dizgesine uyum sağlayacak bir yaklaşımla birleştirilmesi üzerinde yoğunlaştığı görülmektedir.

\subsection{Yöntem}

Çalışmanın çözümleme kısmında, kaynak metin ile erek metinler, André Lefevere'in tüm yeniden yazma eylemlerinin belli bir ideolojik görüşü yansıttığı ve belli bir poetikaya bağlı olarak üretildiği, bundan dolayı da edebiyat dizgesini yönlendirme gücüne sahip olduğunu belirten görüşü göz önünde bulundurularak, zamana bağlı poetik farklılıkları ve bağlama bağlı ideolojik farklılıkları ele vermesi açısından Marilyn Gaddis-Rose'un önerdiği “üç boyutlu okuma" yönteminde vurgulandığı gibi kaynak ve erek metinlerin birlikte deneyimlenmesiyle incelenecektir.

\section{Bulgular}

İncelemede kullanılan metinlerden kaynak metin olan The Glass Menagerie KM olarak, Can Yücel'in çevirisi olan erek metin Sırça Kümes EM1 olarak, Aytuğ İzat'ın çevirisi olan erek metin Sırça Hayvan Koleksiyonu EM2 olarak anılacaktır. Aynı şekilde çevirmen Can Yücel'den Ç1, çevirmen Aytuğ İzat'tan Ç2 olarak söz edilecektir. Ayrıca inceleme sırasında erek metinler ve kaynak metinden alınan bölümler, ifade özelliklerine göre gruplanarak, kelime seçimleri ve yapısal anlam özelliklerine göre eleştirel bakış açısıyla irdelenecektir.

\subsection{Argo Kullanımı}

Örnek 1

EM1: AMANDA: Ağzını koparırım senin!

EM2: AMANDA: Sakın buna başlamaya cesaret etme...

KM: AMANDA: Don't you DARE to-

EM1'de "ağzını koparırım senin" ifadesi yer almaktadır. EM2'de ise "sakın buna başlamaya cesaret etme" ifadesi kullanılmıştır.

Ç1, karakterin konuşma dili düzeyini düşürmeyi uygun görmüş ve argo kullanımına yönelmiştir. Ç1'in bu yönelimi erek seyircinin tartışmanın ciddiyetini anlaması uğruna yapmış olduğu bir hamle olabilir. Ç2 ise, KM'de yer alan "Don't you dare to-_" ifadesini sözcük anlamlarıyla erek metnine aktarmayı tercih etmiştir.

\section{Örnek 2}

EM1: AMANDA: Her neyse olanlar bana olcak yine. İt gibi çalışacağım. Ele güne mahçup olmıyalım da razıyım ben her şeye.

EM2: AMANDA: Aslında bunun tek anlamı var, o da benim canımı dişime takıp çalışmam demek. Muhteşem olmayabiliriz, ama teftişten de geçeriz!

KM: AMANDA: It simply means I'll have to work like a Turk! We won't be brilliant, but we will pass inspection. 
EM1'de "it gibi çalışırım” ifadesi yer alırken EM2'de "canımı dişime takıp çalışırım" ifadesine yer verilmiştir.

Ç1, "it gibi çalışmak" ifadesiyle argo dil kullanımını tercih etmiş ve ideolojik bir gönderme yapmak istemiş olabilir. Ç2 ise, KM'de yer alan ve kaynak dilde yaygın kullanımı olan "work like a Turk" deyimini erek dilde yaygın olarak kullanılan "canını dişine takarak çalışmak" deyimiyle karşılamayı uygun görmüştür.

\section{Örnek 3}

EM1: JIM: Elektriği kestikleri zaman anlarsın sen Hanyayı Konyayı!

EM2: JIM: Elektriği kestiklerinde bunu yaptığına pişman olacaksın.

KM: JIM: You will regret it when they turn the lights off.

EM1'de "anlarsın sen Hanyayı Konyayı" ifadesi yer alırken EM2'de "pişman olacaksın" ifadesi kullanılmıştır.

Ç1, KM'de yer alan "regret it" ifadesini erek dildeki argo kullanımıyla karşılamayı tercih etmiştir. Bu tercihin sebebi, kaynak dildeki tehditkâr söylemi erek dizgenin konuşma dilini metne ve oyuna yansıtarak karşılamak istemesi olabilir. Ç2 ise, bu ifadeyi sözcük anlamıyla aktarmayı uygun görmüştür.

\subsection{Deyim Kullanımı}

\section{Örnek 1}

EM1: AMANDA: Ahhh, ah!... Başımdan kaynar sular boşaldı, dizlerimin bağ1 çözülüverdi.

EM2: AMANDA: Ah! Öylesine güçsüz hissettim ki kendimi, zorla ayakta durabildim!

KM: AMANDA: I felt so weak I could barely keep on my feet!

EM1'de "Başımdan kaynar sular boşaldı, dizlerimin bağı çözülüverdi." ifadesi, EM2'de “Öylesine güçsüz hissettim ki kendimi, zorla ayakta durabildim!” ifadesi yer almaktadır.

Ç1, iki deyimi peş peşe kullanarak sahnedeki dilin akıcılığını güçlendirmek istemiş olabilir. Ç2 ise, kaynak metinde yer alan sözcüklerin anlamlarına göre bir aktarım gerçekleştirmeyi tercih etmiştir.

\section{Örnek 2}

EM1: AMANDA: İş, Mr. Garfinkel'in surat asmasına kalsın! Canımızı alacak değil ya!

EM2: AMANDA: Taş ve sopa kemiklerimizi kırabilir, ama Bay Garfinkel'in asık suratı bize zarar vermez.

KM: AMANDA: Sticks and stones can break our bones, but the expression on $\mathrm{Mr}$ Garfinkel's face won't harm us!

EM1'de “canımızı alacak değil ya!” ifadesi yer almaktadır. EM2' de “taş ve sopa kemiklerimizi kırabilir" cümlesi kullanılmıştır. 
Ç1, KM’de yer alan deyim kullanımını bu ifadeyi “canımızı alacak değil ya!” cümlesiyle karş1layarak deyimsel bir ifade kullanma yolunu tercih etmiştir. Ç2 ise, sözcüklerin erek dildeki karşılıklarıyla ifade etmeyi tercih etmiştir. Ç2'nin amacı yerelleştirmeden uzak durmak ve seyirciyi yönlendirmemek olabilir.

Örnek 3

EM1: AMANDA: Kendimi sürmüyorum öne, görüyorsun! Bir ayağım çukurda zaten. Ben nasıl olsa olurum. Ama Laura öyle mi ya!... Genç daha, üstelik bakılmaya muhtaç. EM2: AMANDA: Kendimi katmıyorum, çünkü ben yaşlıyım ve artık benim için fazla fark etmez! Kardeşini söylüyorum; çünkü genç ve bize bağımlı biri o.

KM: AMANDA: I don't say me because I'm old and don't matter-I say for your sister because she's young and dependent.

EM1'de "bir ayağım çukurda zaten" ifadesi yer alırken EM2'de "ben yaşlıyım” ifadesi tercih edilmiştir.

Ç1, KM'de yer alan "I'm old” ifadesini "bir ayağım çukurda zaten" olarak kullanarak deyimsel bir ifadeyle erek dildeki yayın kullanımdan faydalanarak sahnedeki anlatımı güçlendirme yoluna gitmek istemiş olabilir. Ç2 ise, sözcük anlamıyla aktarmayı uygun görmüş olabilir.

Örnek 4

EM1: TOM: Babama çekmişim ben. Mayam bozuk, soysuzun oğlu soysuz.

EM2: TOM: Ben babama benzerim. Taşa çıkan keçinin ağaca tırmanan oğlağı!

KM: TOM: I'm like my father. The bastard son of a bastard!

EM1'de "mayam bozuk" ifadesi yer almaktadır. EM2' de ise “taşa çıkan keçinin ağaca tırmanan oğlu" ifadesi kullanılmıştır.

Ç1, KM'de yer alan "the bastard son of a bastard" ifadesindeki argo kullanımını "mayam bozuk" eklemesiyle deyimsel bir ifadeyle karşılayarak dil düzeyini devam ettirmek istemiş olabilir. Ç2 ise, "taşa çıkan keçinin ağaca tırmanan oğlu" deyiminin ifade ettiği takip ve devamlılık anlamılla seyirciye olayların gidişatıyla ilgili haber vermek istemiş olabilir. Ayrıca Ç2, KM'de yer alan argo ifadeyi erek metne yansıtmak istememiş ve anlatımdaki akıcılı̆̆ deyim kullanımıyla ifade etmek istemiş olabilir.

\subsection{Sahnelenme Sürecine Yönelik İfadeler}

Örnek 1

EM1: Tom gemici k1lığiyle, soldaki ara sokaktan içeri girer sahnenin önünden geçip yangın merdivenine yollanır. Oracıkta durur, bir sigara yakar. Sonra seyircilerle konuşmağa başlar.

EM2: Tom gemici kılığında gelip, yangın merdivenlerinin etrafında oyalanırken, bir sigara yakar ve seyircilere doğru konuşmaya başlar. 
KM: Tom enters dressed as a merchant sailor from alley, stage left, and strolls across the front of the stage to the fire-escape. There he stops and lights a cigarette. He addresses the audience.

EM2'de "stage left" yönlendirmesine yer verilmezken, EM1'de "soldaki ara sokaktan" ifadesi kullanılmaktadır. EM2' de "strolls across the front of the stage to the fire-escape" ifadesi "yangın merdivenlerinin etrafında oyalanırken” olarak kullanılmıştır. EM1'de ise "sahnenin önünden geçip yangın merdivenine yollanır" ifadesi yer almaktadır.

Ç1, hem "soldaki" hem de "sahneninin önünden geçip" ifadeleriyle metinde yer alan yönlendirmeleri kullanarak oyunun sahnelenmesi sürecinde kaynak metnin izlenebilmesine imkân tanımıştır. Ç2, erek kültürdeki yönetmen ve oyuncuların metni daha rahat kullanabilmelerini sağlayacak olan sahne yönlendirmelerini kullanmayı tercih etmemiştir.

\section{Örnek 2}

EM1: Laura, annesinin halini görünce, şaşkınlıktan elini ağzına götürür.

EM2: Annesinin bu halini gören Laura, heyecanlanıp dudaklarını kemirmeye başlar.

KM: Then she slowly lets herself in the door. Seeing her mother's expression Laura touches her lips with a nervous gesture.

EM1'de "şaşkınlıktan elini ağzına götürür” ifadesi yer alırken, EM2'de "heyecanlanıp dudaklarını kemirmeye başlar" ifadesi kullanılmıştır.

Ç1, KM'de yer alan "touches her lips with a nervous gesture" ifadesini "şaşkınlıktan elini ağzına götürdü” sözcüğüyle karşılamayı uygun görmüş olabilir. Ç1, erek metninde karakteri daha kibar tavırlar içinde yansıtmak istemiş olabilir. Ç2 ise, "heyecanlanıp dudaklarını kemirmeye başlar” olarak karşılayarak sahnede yükselmekte olan tansiyonu abartılı bir yönlendirmeyle oyuncunun hareketlerine taşımak istemiş olabilir.

Örnek 3

EM1: JIM: Şey işte... Konuşup ettiğim genç kız. (Tatlı tatlı gülümser. Amanda'nın başına dünyalar yıkılır.)

EM2: JIM: Şey, sadece bir kız. Devamlı çıktığım biri! (Tatlı tatlı gülümser. Yă̆mur boşalır.)

KM: JIM: Oh, just a girl. The girl I go steady with [He smiles charmingly. The sky falls.]

EM1'de “Amanda'nın başına dünyalar yıkılır” ifadesi kullanılmış, EM2'de “yağmur boşalır" ifadesine yer verilmiştir.

Ç1, KM'de yer alan sahneleme yönlendirmesi "the sky falls" ifadesinin yan anlamını kullanmayı uygun görerek “Amanda'nın başına dünyalar yıkılır” ifadesiyle sahneleme sürecine müdahale etmek istemiş olabilir. Ç2 ise, KM'deki ifadenin sözcük anlamına göre erek metne aktarmıştır. 


\subsection{Erek Kültüre Özgü İfadeler}

Örnek 1

EM1: TOM: Bir kişi daha var ama, oyunda görünmüyor; sade duvarda asılı fotoğrafını gördüğümüz kadarıyla oyuna katılıyor: Bizleri yıllar önce bırakıp giden babamız. Telefoncuydu. (Şehirlerarası santralında çalışırken) ırak yerlere kaptırdı gönlünü. Bir gün telefon kumpanyasında Allahaısmarladığı çektiği gibi ortadan kayboluverdi. Neden sonra bir kartpostal aldık; Meksika'da Mazatlan diye bir yerden yollamış. Bir daha ne bir haber ne bir mektup... Kartpostal da iki kelimelik bir şey: "Merhaba... Hoşça kalın!...” Adres de yok sonunda...

EM2: TOM: Oyunda bir de beşinci karakter var; kendisi şöminenin üzerinde asılı olan ve gerçeğinden daha büyük bu fotoğrafının dışında, oyunda asla görünmez. Bizi yıllar önce terk eden babamızdır bu kişi. Telefoncuydu ama uzak diyarlara âşıktı, çalıştığı telefon firmasından ayrıııp, ışı delisi bu şehirden sıvışıp gitti... Ondan aldığı̆ız en son haber, Meksika'nın Pasifik kıyılarında Mazatlan'dan gönderilen adressiz bir kartpostaldı ve üzerinde sadece iki kelime yazılıydı. "Merhaba... Hoşça kalın!"

KM: TOM: There is a fifth character in the play who doesn't appear except in this larger-than-life-size photograph over the mantel. This is our father who left us a long time ago. He was a telephone man who fell in love with long distances; he gave up his job with the telephone company and skipped the light fantastic out of town... The last we heard of him was a picture postcard from Mazatlan, on the Pacific coast of Mexico, containing a message of two words -'Hello - Good-bye!' and no address.

EM1'de "Allahaısmarladığı çektiği gibi ortadan kayboluverdi" ifadesinin kullanımı yeğlenmiştir. EM2'de ise "1şık delisi bu şehirden sıvışıp gitti" ifadesi yer almıştır.

Ç2, KM'de yer alan "mantel" ifadesini "şömine" olarak KM'de yer alan ifadeyi anlam kaymasına yol açmadan karşılarken Ç1, bu ifadeye yer vermemiştir. Ç1, orta-aşağı-sınıf olarak nitelendirilen bir ailenin evinde şömine olmasının erek seyircinin algısına ters düşeceğini düşünmüş olabilir. Ç1, KM'de "skipped the light fantastic out of town" ifadesini "Allaha ısmarladığı çektiği gibi ortadan kayboluverdi” ifadesiyle erek dile özgü olan ve sıkça kullanılan bir vedalaşma söylemiyle erek seyircinin oyunla daha rahat bütünleşmesini hedeflemiş olabilir. Ç2 ise, "Işık delisi bu şehirden sıvışıp gitti”" ifadesini kullanarak karşılamıştır. Ç2, erek seyircinin zihninde canlanması muhtemel şehir imgesine müdahale etmek istemiş olabilir. Ç1, KM'de yer almayan "adres de yok sonunda" ifadesiyle anlatıcının akıcılı̆ı̆ını devam ettirmek istemiş ve erek seyirciye durumu kesin bir ifadeyle açıklamak istemiş olabilir.

\section{Örnek 2}

EM1: AMANDA: Kaarun gibi bir şey... Neye dokunsa hani, altın kesilecek neredeyse. EM2: AMANDA: Sanki Midas'ın sırrı onda, neye dokunsa altın kesiliyor.

KM: AMANDA: He had the Midas touch, whatever he touched turned to gold! 
EM1'de "kaarun" sözcüğü uygun görülmüştür. EM2' de "Midas" ifadesine yer verilmiştir.

Ç1, KM'de yer alan "Midas touch" ifadesini "kaarun” sözcüğüyle karşılayarak, kaynak dilde yaratılan benzetmeyi erek seyirciye daha tanıdık geleceğini düşündüğü bir imge ile karşılamaya çalışmış olabilir. Ç2 ise, "Midas’ın sırrı" ifadesiyle karşılayarak sözcük anlamlarına göre EM2'de var etmeyi tercih etmiş olabilir.

\section{Örnek 3}

EM1: AMANDA: Allah yardımcın olsun, kardeş!... Ne diyeyim bilmem ki... Hastalık sağlık hep bizim için ama ne bitmez çileymiş bu seninkisi canım...

EM2: AMANDA: Tanrı yardımcın olsun! Sen inançlı bir Hıristiyansın, evet evet iyi bir Hiristiyansın!

KM: AMANDA: Heaven have mercy! You're a Christian martyr, yes, that's what you are, a Christian martyr!

EM2'de "Sen inançlı bir Hıristiyansın, evet evet iyi bir Hıristiyansın" ifadesi bulunurken EM1'de bu ifadeye rastlanmamaktadır.

Ç1, KM'de yer alan "heaven have mercy” ifadesini erek kültürüdeki yaygın inanış ve erek dildeki yaygın kullanımı göz önünde bulundurarak "Allah yardımcın olsun, kardeş” ifadesini tercih etmiş olabilir. Ç2 ise, "Tanrı yardımcın olsun” olarak aktarmıştır. Sonrasında yer alan "You're a Christian martyr, yes, that's what you are, a Christian martyr" ifadesini Ç2, erek metnine "Sen inançlı bir Hıristiyansın, evet evet iyi bir Hıristiyansın" olarak aktarmayı uygun görürken Ç1, bu ifadeye yer vermeyerek erek metinde eksiltmeye neden olmuş ve bu kaynak metinde bulunan ifadeyi "Ne diyeyim bilmem ki... Hastalık sağlık hep bizim için ama ne bitmez çileymiş bu seninkisi canım...” cümleleriyle karşılamayı yeğlemiştir.

\subsection{Kaynak Kültürre Özgü İfadeler}

\section{Örnek 1}

EM1: TOM: Jim o zamanlar Hayskulun gözde öğrencisiydi. Canlı, öyle cana yakın, pirıl pirıl bir delikanlı.

EM2: TOM: Jim, lisedeyken bir kahramandı. Öylesine İrlandalı bir görünüşe ve canlılığa sahipti ki, iyice partılmış ve cilalanmış bir Çin tabağını andırırdı. Sanki üzerinde bir 1şık demetiyle dolaşırdı.

KM: TOM: In high school Jim was a hero. He had tremendous Irish good nature and vitality with the scrubbed and polished look of white chinaware. He seemed to move in a continual spotlight.

EM1'de "hayskulun" ve "canlı" ifadeleri yer alırken EM2'de "lisedeyken", "Çin tabağı" ifadeleri kullanılmıştır.

Ç1, "hayskulun" sözcüğünü kaynak dilde yer aldığı şekilde EM1'ye aktarmayı uygun görerek erek dil dizgesine ait olmayan ve anlaşılmaz bir sözcükle anlam kaymasına neden 
olmuştur. KM'de yer alan "Irish" ifadesine EM1'de yer vermeyen Ç1, betimleyici anlatımı da sadeleştirmiştir. Ç1, "hayskul” kullanımından sonra metnin yabancılığını pekiştirmemek adına sıfatları akıcı bir dille aktarmak istememiş olabilir. Ç2, KM'de yer alan "chinaware" ifadesini sözcük anlamına göre çevirmeyi tercih etmiş ve anlam kaymasına neden olmuştur.

\section{Örnek 2}

EM1: JIM: Yunikorn ha?

EM2: JIM: Tek boynuzlu atımsı bir şey bu, "Unicorn” galiba?

KM: JIM: An unicorn, huh?

EM1'de "yunikorn" ifadesi yer alırken EM2'de "tek boynuzlu atıms1" ve "unicorn" ifadeleri kullanılmıştır.

Ç1, KM'de yer alan "unicorn” sözcügüüü kaynak dil dizgesine ait sözcügü erek dildeki okunuşuyla "yunikorn" olarak aktarmayı tercih etmiştir. Ç2 ise, önce anlamı doğrultusunda betimlemeyi tercih etmiş sonra da anlatımı bütünlemesi açısından kaynak dildeki sözcüğe yer vermeyi uygun görmüş olabilir. Her iki çevirmen de erek dile ait olmayan kelime seçimleriyle kaynak kültürün görünürlüğünü arttırmak istemiş olabilir.

\subsection{Başlık Seçimi}

Ç1'in başlık seçimi oyunun sahnelenmesine yönelik bir davranış olarak ele alınabilir. Çevirmen Can Yücel, Suat Karantay ile yaptığı ve Metis Çeviri dergisinde yayınlanan röportajında bu seçiminin nedenini şöyle açıklamaktadır: "Hayvanat Bahçesi desen olmaz. Biz onu şöyle yaptık. Ev kümes gibi bir yer ve ben düşündüm ki sahneye konurken kümes mizanseni de tutabilir. Sırça Kümes... Anne kartlamış tavuk gibi, kız bir piliç. Öbür horozlar geliyor. Yani daha tiyatral bir planda düşündüm" (Karantay, 1988: 16). Ç1'in bu sözleri ışığında başlıkta kullandığı "kümes" ifadesi oyunun gerçekleştiği yerle ilgili bir tanım yapmakla beraber, bu seçimiyle yönetmene, dekor tasarımcısına ve oyunculara hitap ettiğini belirterek erek seyircinin alımlamasına yönelik bir seçim olduğunun altını çizmektedir. Ç2 ise, KM'de yer alan hayvan bahçesi göndermesini, oyundaki evin içinde bulunan cam hayvan biblolarını da gözeterek EM2'ye "hayvan koleksiyonu” ifadesini kullanmayı uygun görmüş olabilir.

\section{Tartışma ve Sonuç}

Ç1'in erek metne yansıttığı davranışlar arasında erek dil kullanımında gözettiği davranışların başında KM'de yer alan sembollerin aktarımında erek dil kullanımı, erek seyircinin metinle iletişim kurmasını sağlamak için erek kültür öğelerini kullanma ve sahnelemeye yönelik notların erek metne aktarma eğilimi gözlenmektedir. Erek seyircinin günlük dil kullanımında sıklıkla karşılaştığı argo sözcük kullanımı durumuna örnek olarak gösterilebilecek kullanımlara başvurmuştur. Ç1'in aynı söyleşide Amanda karakterinin sözlerinde argo kullanımı üzerinde sorulan soruya verdiği yanıt şudur: "Argo konuşma değil o aslında. Kibarlık içinde yırtıcı, 
çığırtkan bir kadın Amanda. Küfür yok. Sert bir dil çünkü yıkıcı bir kadın. Güneyli bir kibarlık budalası" (a.g.e.: 16). Ç1, argo söz kullanımı ve erek dile özgü deyimlerin kullanımıyla karakterlerin alt metinde vurgulanan kişiliklerini EM1'e yansıtmak, kaynak metni erek seyirciye anlaşılır kılmak ve erek seyircinin kaynak seyirciyle ortak bir deneyimi yaşamasını sağlamayı hedeflemiş olabilir.

Ç2'nin gözlemlenen çevirmen davranışları olarak KM'de yer alan ifadeleri kesintisiz olarak erek metne aktarma, erek kültür dizgesine ait deyimsel ifadeler kullanma ve erek dil dizgesinde yaygın olarak kullanılan günlük konuşma dilinden faydalanma sıralanabilir. Ç2'nin erek dilin günlük dil kullanımını uyguladığı argo sözcük seçimleri, erek dil dizgesine özgü deyimsel ifade kullanımı ve erek kültür öğelerini kullanımı ile erek seyirciye kaynak metnin yabancılığını hissettirmek adına tercih etmiş olabilir.

Karakterlerin konuşma dilini erek metne yansıtan Can Yücel, erek dilin günlük kullanımında göze çarpan deyim ve argo dil etmenlerinden yararlanmıştır. Can Yücel'in bu davranışı, erek seyircinin kaynak dil ve kültür dizgesine ait olan bir eser karşısında yabancılık çekmesini engelleme çabası olarak değerlendirilebilir. Sahneleme notlarını gözeten Can Yücel, Williams’ın oyun yazarı olarak kaynak metinde yer verdiği yönlendirmeleri erek metne yansıtarak sahnelenmeye hazır bir metin yaratmıştır.

Günlük dil kullanımını kaynak metinde yer alan sözcüklerin anlamları dahilinde kullanan Aytuğ İzat, kaynak dizgenin dilsel ve kültürel özelliklerini korumaya ve erek seyirciye hissettirme isteği EM2'de gözlemlenmektedir. Kaynak dil ve kültür dizgesini koruyan ve dolayısıyla kaynak odaklı bir çeviri olarak ele alınabilecek olan EM2, göz ard1 ettiği sahneleme notları ve oyuncu yönlendirmeleriyle sahneleme sürecinde yönetmen kararlarının öne çıkabileceği bir metin olarak değerlendirilebilir.

Sonuç olarak kaynak metnin farklı okuma süreçleri doğrultusunda çevirmenler tarafından farklı yorumlanmasından oluşan farklılar, her iki erek metne yansımıştır. Bu farklılıklar, erek dil ve kültür dizgesini zenginleştiren ve geliştiren çevirmen kararları olarak kabul edilmiştir. Çalışmanın amacı dahilinde çeviri süreçlerinin şekillendirilmesinde ve çevirmen söylemlerinin farklılarının erek dizgede gözlemlenebilmesi üzerinde yapılan kaynak metin ve erek metinlerin incelemesi sonucunda, farklı bir dil ve kültür dizgesine ait olan kaynak metin The Glass Menagerie'nin etkisinin, yeniden yazma bağlamında yorum ve çeviri anlayışı farklılıklarını erek metinlerine yansıtan çevirmenler Can Yücel ve Aytuğ İzat sayesinde erek dizgede de yeniden var edilmiştir. Ancak yapılan incelemede kaynak kültür ve erek kültür arasındaki yolu çizen ve erek dil dizgesi dahilinde şekillenen bu yolun şartlarına göre yolculuk yapan çevirmenlerin, aynı kaynaktan beslenmelerine rağmen farklı varış noktalarına ulaştıkları ve aynı kaynağı kendilerine has biçimleriyle yeniden yazdıkları sonucuna ulaşılmıştır. Erek dizgede kendine yer edinmiş olan ve varlığını koruyan bu oyun metinleri, tiyatro salonlarından seyirciyle buluşmaya devam etmektedir. Kaynak metinlerin erek dizgelerde birden fazla eserle temsil edilmesi hem okur hem de dizge açısından önem taşımaktadır. Bu çeşitliliğin oluşturduğu 
zenginlik sayesinde edebiyat dizgelerinin gelişmesi, okurların ve seyircilerin ilerlemesi ve düşünce alanlarının genişlemesi mümkün olacaktır.

Hakem Değerlendirmesi: Dış bağımsız.

Çıkar Çatışması: Yazar çıkar çatışması bildirmemiş̧ir.

Finansal Destek: Yazar bu çalışma için finansal destek almadığını beyan etmiştir.

Peer-review: Externally peer-reviewed.

Conflict of Interest: The author has no conflict of interest to declare.

Grant Support: The author declared that this study has received no financial support.

\section{KAYNAKÇA/REFERENCES}

Bassnett, S. (2002). Translation Studies, Routledge.

Bassnett, S. \& Lefevere, A. (1998). Constructing Cultures: Essays on Literary Translation, Multilingual Matters Ltd.

Bassnett, S. \& Lefevere, A. (1992) Translation, History, Culture, Routledge.

Dinçel, M. (2016). Yeniden Yazılan Metinler: Sirça Kümes ve Sirça Hayvan Koleksiyonu Oyunlarının Oyun Çevirisi Bağlamında İncelenmesi. Tez (YL). İstanbul: İstanbul Okan Üniversitesi (yayımlanmamış).

Ece, A. F. (2010). Edebiyat Çevirisinin ve Çevirmeninin İzinde, Sel Yayınc1lı.

Gaddis-Rose, M. (1997). Translation and Literary Criticism: Translation As Analysis, St. Jerome Publishing. İzat, A. (2000). Strça Hayvan Koleksiyonu, Mitos Boyut.

Lefevere, A. (1992). Translating, Rewriting and Manipulation Literary Fame, Routledge.

Karantay, S. (Yaz 1989). “Can Yücel ile Söyleşi”, Metis Çeviri 8: 11-19.

Pavis, P. (1999). Sahneleme: Kültürler Kavşağında Tiyatro, Kamber, S. (çev.), Dost Kitabevi Yayınları.

Williams, T. (2009). The Glass Menagerie, Penguin Books Ltd.

Yücel, C. (1964). Sirça Kümes, Millî Eğitim Bakanlığı Yayınları. 